\title{
BLOOD COLLECTION AND USAGE DURING CORONAVIRUS OUTBREAK
}

\author{
NOOR HASLINA MOHD NOOR ${ }^{* 1,3}$, HISHAM ATAN EDINUR ${ }^{2,3}$, ZEFARINA ZULKAFLI $^{1,3}$, \\ CHE GHAZALI NORUL HAJAR ${ }^{2}$, SALFARINA IBRAHIM ${ }^{1,3}$, MARINI RAMLI AND MOHD \\ NAZRI HASAN ${ }^{1,3}$
}

${ }^{1}$ School of Medical Sciences, Universiti Sains Malaysia, 16150 Kubang Kerian, Kelantan. ${ }^{2}$ School of Health Sciences, Universiti Sains Malaysia, 16150 Kubang Kerian, Kelantan. ${ }^{3}$ Hospital Universiti Sains Malaysia, Health Campus, Universiti Sains Malaysia, 16150 Kubang Kerian, Kelantan.

*Corresponding author: drhaslina@usm.my

Submitted final draft: 29 July $2020 \quad$ Accepted: 9 August 2020

http://doi.org/10.46754/jssm.2021.01.003

\begin{abstract}
A significant concern of the coronavirus disease 2019 (COVID-19) pandemic is the dramatic decrease in the number of blood donation drives across Malaysia. The pandemic is putting a strain on the blood inventory and supply, especially to transfusiondependent patients; i.e., thalassemia major, sickle cell disease and cancer patients. This is a retrospective cross-sectional study carried out at the Transfusion Medicine Unit, Hospital USM from December 2019 to April 2020. Data on blood donation and blood component usage were collected and tabulated three months (18th December 2019 to 17th March 2020) before movement control order (MCO) and during the first phase of MCO (18th March to 17th April 2020). Whole blood units that were donated via mobile drives were predominantly affected with the number of blood donors in blood mobiles decreased by $80.7 \%$ during MCO. The decreasing pattern was due to the cancellation of 25 mobile drives, which targeted 1267 blood donors. Blood usage was also escalating down to 840 during the $\mathrm{CO}$, which was due to no elective operations, admissions, or procedures done during the MCO. Routine blood donation and collection thus need to be resumed in less affected areas to meet the clinical needs with greater precaution against COVID-19 infections.
\end{abstract}

Keywords: Blood collection, blood usage, COVID-19.

Abbreviations: Coronavirus disease-2019 (COVID-19), movement control order (MCO), acute respiratory syndrome coronavirus 2 (SARS-CoV-2)

\section{Introduction}

The severe acute respiratory syndrome coronavirus 2 (SARS-CoV-2) is a singlestranded RNA betacoronavirus belonging to the sarbecovirus subgenus of the Coronaviridae family. The virus caused Coronavirus Disease-2019 (COVID-19) outbreak in Wuhan, China and later spread rapidly to other regions, including the Southeast Asian countries (World Health Organisation, 2020a).

The first COVID-19 case in Malaysia was identified at the end of January 2020. After nearly two months, the government decided to enforce movement control order (MCO) to prevent and break the chain of disease transmission (Mat et al., 2020). The MCO started from $18^{\text {th }}$ March to $31^{\text {st }}$ March 2020 (first phase), which was then extended to $14^{\text {th }}$ April 2020 and $30^{\text {th }}$ April
2020 for phase II and III, respectively (Prime Minister's Office, 2020).

During the MCO, people were urged to stay at home and most of the government and private sectors were closed. According to the American Red Cross, about $40 \%$ of blood drives had been cancelled due to SARS-CoV-2 outbreaks, which attributed to about 200,000 blood donations (American Red Cross, 2020a). Even though blood and platelet transfusions are not needed for the treatment of patients infected with the SARS-CoV-2, a sufficient supply of blood and blood products are still needed for patients with sickle cell disease, cancer and for emergency cases such as trauma, severe infant anaemia and urgent surgeries (American Red Cross, 2020b).

Here, we report a pattern of blood donations at Hospital Universiti Sains Malaysia before and 
during the enforcement of the MCO in Malaysia and provide several recommendations that can be adopted by other transfusion centres.

\section{Materials and Methods}

This is a retrospective cross-sectional study carried out at the Transfusion Medicine Unit, Hospital USM from December 2019 to April 2020. Data on blood donation and blood usage (packed red blood cells and platelet) were collected and tabulated three months $\left(18^{\text {th }}\right.$ December 2019 to $17^{\text {th }}$ March 2020) before the MCO and during the first phase of the MCO (18 ${ }^{\text {th }}$ March to $17^{\text {th }}$ April 2020).

Most of the donor selection and deferral criteria are similar between those collected before and during the $\mathrm{MCO}$, which include voluntary non-remunerated blood donation, lifestyle, medical history, hemoglobin level ( $>120 \mathrm{~g} / \mathrm{L}$ for women and $>130 \mathrm{~g} / \mathrm{L}$ for men) and normal blood pressure (Saleh et al., 2018). However, additional criteria for blood donation were included during the MCO. These are an extension of existing guidelines of donor selection such as being healthy (without flu, cold, cough and breathing issues), no travelling history abroad since December 2019, no contact with COVID-19 confirmed cases and not involved in any social, cultural and religious events including the Sri Petaling gathering (Mat et al., 2020). Information was obtained via a questionnaire and a short interview session with a medical officer. Then, approximately around $450 \mathrm{ml}$ of whole blood was collected from each qualified donor. The collected blood was then subjected to blood grouping, screened for potential transfusion-transmitted diseases and fractionated to red cell concentrate and platelets before releasing for transfusion procedures.

\section{Results and Discussion}

The Transfusion Medicine Unit, Hospital USM, is a tertiary care blood centre catering to a 900-bedded teaching hospital in the Kelantan State. We had collected a total of 1124, 1028, and 1229 whole blood units three months
(18 $8^{\text {th }}$ December 2019 to $17^{\text {th }}$ March 2020) before the MCO was enforced in Malaysia. However, during the MCO $\left(18^{\text {th }}\right.$ March to $17^{\text {th }}$ April 2020), only 303 whole blood units were collected (Figure 1). This was mainly due to the cancellation of 25 mobile drives, which targeted around 1267 units of blood donation. Our data showed that the source of whole blood units donated via mobile blood drives was severely affected in a month of during the MCO and the number of blood donors decreased to more than $70 \%$ from the average units collected three months before the MCO.

Tsubokura et al. (2010) examined the effect of blood donation during the influenza A H1N1 outbreak in 2009. According to the study, the number of blood donors decreased by $21 \%$ and whole blood donations declined by 1329 units within just a week. However, it was a transient phenomenon and blood donations returned to the average level within one week after the influenza A H1N1 was contained (Tsubokura et al., 2010). Similar observations were reported at blood donation centres in major cities of China, where they faced unprecedented challenges of blood supply for clinical usage during the 2009 influenza A H1N1 outbreak (Cai et al., 2020).

It is obvious that disease outbreak has an adverse impact on our healthcare delivery systems, including transfusion services. In this context, blood donor centres are likely to lose many blood units collected via their regular blood recruitment strategies. The situation will become more complicated with the enforcement of the MCO and even worsen if the affected areas are completely locked down, the two public preventive measures that are commonly practised in many countries to contain the spread of SARS-CoV-2 in the communities (Kamp et al., 2010; American Red Cross, 2020a).

Packed red blood cell and platelet usage before and during the MCO are shown in Figures 2 and 3, respectively. In general, demands for packed red blood cells and platelets dropped by $15 \%$ and $31 \%$ during the MOC, respectively. However, the decreasing patterns of packed red blood cell and platelet usage are far below 
the number of blood donation losses during the MCO (i.e., 70\% from the average units collected before the MCO). In this context, blood services should monitor closely their blood inventories so that measures can be taken quickly if there is a decline in donor attendance or a shortage of the components. This is particularly critical for platelets, which have a shorter shelf life and a constant supply is needed for thrombocytopenic patients that are dependent on regular platelet transfusions (Zimrin \& Hess, 2007; World Health Organisation, 2020b). The SARS$\mathrm{CoV}-2$ has a long incubation period, generally from 1-14 days, but some can be up to 24 days (American Red Cross, 2020b; Lauer et al., 2020). This has resulted in an asymptomatic infection in a large number of individuals and may contribute to additional risk to health workers and blood supply. The strictly implemented mobility constraints further reduce the number of available volunteers for mobile blood drives (Cai et al., 2020).

Our hospital has taken a few actions to overcome the shortage of blood supply; i.e., scale down the clinic follow up, hospital admission and elective operation and procedures, which have resulted in reduced packed red blood cell and platelet usage during the MCO. Similarly, in Washington State, during the first two weeks of COVID 19 pandemic, the hospital kept the inventory stable by getting blood from blood centres of non-affected areas, triaging of blood orders to monitor and prioritise blood utilisation and postponement of electives procedure (Pagano et al., 2020). According to WHO (2020b), as the health care system shifts toward treating COVID-19 patients, elective surgeries and nonurgent clinical interventions can be deferred, so the demand for blood and blood components can be reduced. However, blood transfusions will still be necessary for emergencies such as trauma, post-partum haemorrhage, blood dyscrasias, and urgent surgeries requiring the availability of blood. Kamp et al. (2010) analysed data on the management of blood supplies during an influenza pandemic from several major blood donation services in Germany. It was observed that the severity of blood or blood product shortages during the influenza pandemic depends on detailed knowledge about the fraction of transfusions and criteria for prioritisation of transfusions. It was reported that the pandemic not only reduced the availability of blood supply, but also staff capacity at three German blood centres (Kamp et al., 2010). However, hospital admissions and transfusion procedures were reported to be reduced during the pandemic and helped to balance the reduced blood donation patterns at these blood centres (Zou, 2006). In addition, the hospital should also consider implementing other strategies for maintaining the efficiency of their blood transfusion services. Our National Blood Centre has come out with Guidelines on Transfusion Practice during COVID 19 outbreak which has encouraged the implementation of patient blood management (PBM) to reduce the need for allogeneic blood components. The PBM aims to improve patient outcome and safety by reducing the number of unnecessary red blood cell transfusions and vitalising patientspecific anaemia reserves. Implementation of PBM will optimise the available and limited resources during this outbreak. Treatments such as erythropoiesis-stimulating agents, parenteral iron and vitamin supplements are the pillars in PBM implementation to improve red cell mass and is a safe and effective way of correcting anaemia in a variety of major surgical interventions (National Blood Centre Malaysia, 2020). PBM can be adopted to reduce the need for allogeneic blood components. PBM is an evidence-based programme to optimise medical and surgical patient outcomes by clinically managing and preserving a patient's own blood and managing patients with non-transfusion modalities (Shander et al., 2020).

In order to maintain the efficiency of blood services, we need to encourage more people to come for blood donation and promotions were delivered via e-mail, newspaper, social media such as Facebook, Instagram and WhatsApp group, multimedia campaigns, global email to USM staff and students and requesting for blood mobile drives in low-risk workplaces and universities. Every day about 20-30 donors 
turned up at our Transfusion Medicine Unit for blood donation. Similarly, in Kobe, quick blood donation recovery was attributed to the diligent efforts, including the use of e-mail to encourage blood donation, on-the-street campaigns, and requesting new blood mobile drives at workplaces and tertiary institutions (Tsubokura et al., 2010). However, several approaches adopted by Tsubokura et al. (2010) were not allowed during the $\mathrm{MCO}$, and we resorted to online platforms for promotion purposes.

It is important to note that preventive measures against COVID-19 infection were also practised in our transfusion unit. We have implemented the following new protective procedures; (1) temperatures of staff and donors are checked before entering a donation centre to make sure they are healthy, (2) hand sanitizer is provided to be used before the drive and throughout the donation process, (3) change in the style of waiting, line chairs and space between beds, to maintain social distancing practices between blood donors, (4) all the contacting surfaces are disinfected (5) information obtained from donors by asking whether they or their relatives have COVID-19 symptoms, or have travelled to areas with local transmission of SARS-CoV-2 within 28 days or have attended social and religious events that were identified as COVID-19 clusters by the Ministry of Health. According to the American Association of Blood Banks (2020), donor screening and deferral can be more restrictive as compared with the regular criteria, and deferral policies can be applied based on local concerns such as implementing a travel deferral. As the infection continues, few points may be relevant to be considered regarding transfusion: most younger adult patients who could donate blood had milder symptoms than the older adults and COVID 19 asymptomatic patients/ carriers can donate blood and the rate of infectivity of patients who are in the incubation period remains uncertain (Chang, et al., 2020).

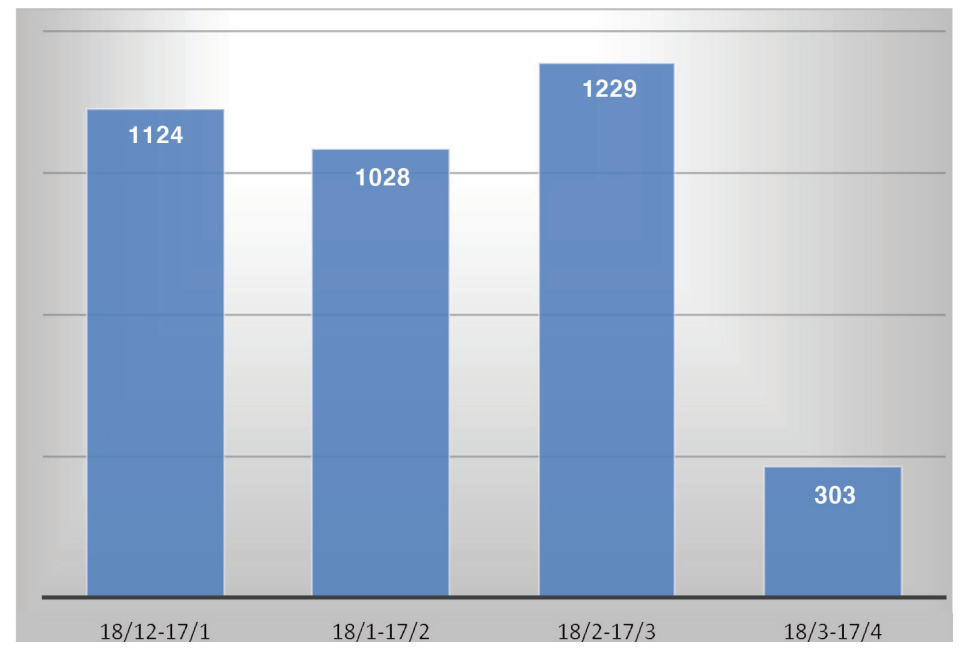

Figure 1: Blood collection before and during $\mathrm{MCO}$ 


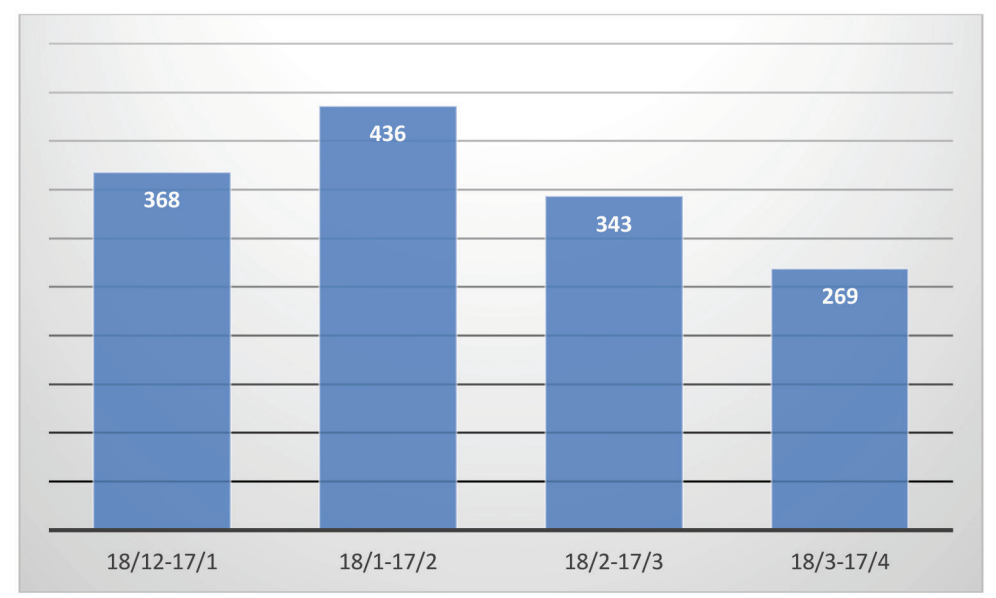

Figure 2: Packed red blood cell usage before and during MCO

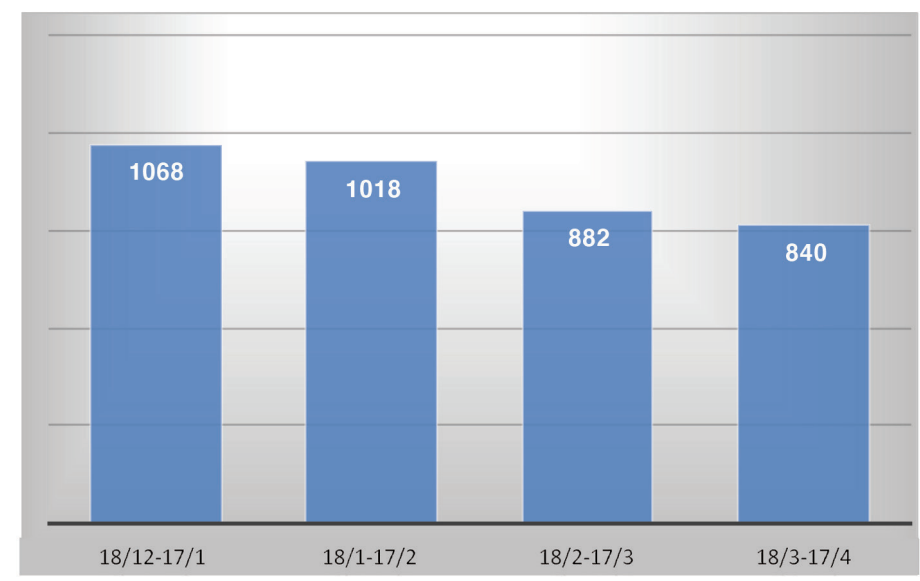

Figure 3: Platelet usage before and during $\mathrm{MCO}$

\section{Conclusion}

Routine blood donation and collection need to be resumed in the less affected areas, with greater precautions against COVID-19 infections. Blood collection centre should ensure that blood collection meets the clinical needs and maintains the safety of staff and blood donors. However, additional criteria for blood donation are needed during a pandemic. This possibly includes rapid testing for COVID-19 antibodies on the potential donors.

\section{Acknowledgements}

The Authors would like to thank Pn Faizatul Syima and Pn, Salamah for their precious assistance with data collection and analysis.

\section{References}

American Association of Blood Banks (2020). Impact of 2019 Novel Coronavirus and Blood Safety. Retrieved from American Association of Blood Banks website: https://www.aabb.org/advocacy/ regulatorygovernment/Documents/Impactof-2019-Novel-Coronavirus-on-BloodDonation.pdf. 
American Red Cross (2020a). During Coronavirus Outbreak, Red Cross Mission Continues: We Need Your Help [Press release]. Retrieved from https://www. redcross.org/local/south-carolina/about-us/ news-and-events/press-releases/duringcoronavirus-outbreak--red-cross-missioncontinues---we-ne.html.

American Red Cross (2020b). American Red Cross Faces Severe Blood Shortage as Coronavirus Outbreak Threatens Availability of Nation's Supply [Press release]. Retrieved from https://www. redcross.org/about-us/news-and-events/ press-release/2020/american-redcross-faces-severe-blood-shortageas-coronavirus-outbreak-threatensavailability-of-nations-supply.html.

Cai, X., Ren, M., Chen, F., Li, L., Lei, H., \& Wang, X. (2020). Blood transfusion during the COVID-19 outbreak. Blood Transfusion, 18(2), 79-82. https://doi. org/10.2450/2020.0076-20.

Chang, L., Yan, Y., \& Wang, L. (2020). Coronavirus disease 2019: coronaviruses and blood safety. Transfusion Medicine Reviews, 34(2), 75-80. https://doi.org/ 10.1016/j.tmrv.2020.02.003.

Kamp, C., Heiden, M., Henseler, O., \& Seitz, R. (2010). Management of blood supplies during an influenza pandemic. Transfusion, 50(1), 231-239. https://doi. org/ 10.1111/j.1537-2995.2009.02498.x.

Lauer, S. A., Grantz, K. H., Bi, Q., Jones, F. K., Zheng, Q., Meredith, H. R., ( . . .) \& Lessler, J. (2020). The incubation period of coronavirus disease 2019 (COVID-19) from publicly reported confirmed cases: estimation and application. Annals of Internal Medicine, 172(9), 577-582. https:// doi.org/10.7326/M20-0504.

Mat, N. F. C., Edinur, H. A., Razab, M. K. A. A., \& Safuan, S. (2020). A Single Mass Gathering Resulted in Massive Transmission of COVID-19 Infections in Malaysia with Further International Spread.
Journal of Travel Medicine. 27(3), taa059. https://doi.org/10.1093/jtm/taaa059.

National Blood Centre Malaysia (2020). Guideline for Blood Donation Activity and Donor Selection Criteria for the Current COVID-19 Outbreak Situation in Malaysia. Retrieved from http://pdn.gov.my/index. php?option $=$ com_jdownloads\&Itemid $=111$ $\&$ view $=$ finish\&cid $=117 \&$ catid $=15 \&$ lang $=$ ms.

Pagano, M. B., Hess, J. R., Tsang, H. C., Staley, E., Gernsheimer, T., Sen, N., ( . . .) \& Alcorn, K. (2020). Prepare to adapt: blood supply and transfusion support during the first 2 weeks of the 2019 novel coronavirus (COVID-19) pandemic affecting Washington State. Transfusion, 60(5), 908911. https://doi.org/10.1111/trf.15789.

Prime Minister's Office (2020). Perutusan Khas YAB Perdana Menteri [Press release]. Retrieved from https://www.pmo.gov. my/2020/03/perutusan-khas-yab-perdanamenteri-25-mac-2020/).

Saleh, R.M., Zefarina, Z., Che Mat N.R., Chambers GK., Edinur HA. (2018). Transfusion medicine and molecular genetic methods. International Journal of Preventive Medicine, 9:45. https://dx.doi. org/10.4103\%2Fijpvm.IJPVM_232_16.

Shander, A., Goobie, S. M., Warner, M. A., Aapro, M., Bisbe, E., Perez-Calatayud, A. A., (. . .) \& Erhard, J. (2020). Essential Role of Patient Blood Management in a Pandemic: A Call for Action. Anesthesia and Analgesia, 131(1), 74-85. https://doi. org/10.1213/ANE.0000000000004844.

Tsubokura, M., Nakada, H., Matsumura, T., Kodama, Y., Narimatsu, H., Yamaguchi, T., \& Kami, M. (2010). The impact of H1N1 influenza A virus pandemic on the blood donations in Hyogo Prefecture, Japan. Transfusion, 50(8), 1803-1805. https://doi. org/10.1111/j.1537-2995.2010.02641.x.

World Health Organisation (2020a). Coronavirus disease 2019 (COVID-19). [Situation 
Report-73]. Retrieved from https://www. who.int/docs/default-source/coronaviruse/ situation-reports/20200402-sitrep-73covid-19.pdf?sfvrsn=5ae25bc7_2.

World Health Organisation (2020b). Maintaining a safe and adequate blood supply during the pandemic outbreak of coronavirus disease (COVID-19) [Interim guidance]. Retrieved from file:///C:/Users/User/Downloads/ WHO-2019-nCoV-BloodSupply-2020.1eng\%20(1).pdf.
Zimrin, A. B., \& Hess, J. R. (2007). Planning for pandemic influenza: effect of a pandemic on the supply and demand for blood products in the United States. Transfusion, 47(6), 1071-1079. https://doi.org/10.1111/j.15372995.2007.01225.x.

Zou, S. (2006). Potential impact of pandemic influenza on blood safety and availability. Transfusion Medicine Reviews, 20(3), 181189. https://doi.org/10.1016/j.tmrv.2006.03. 001. 